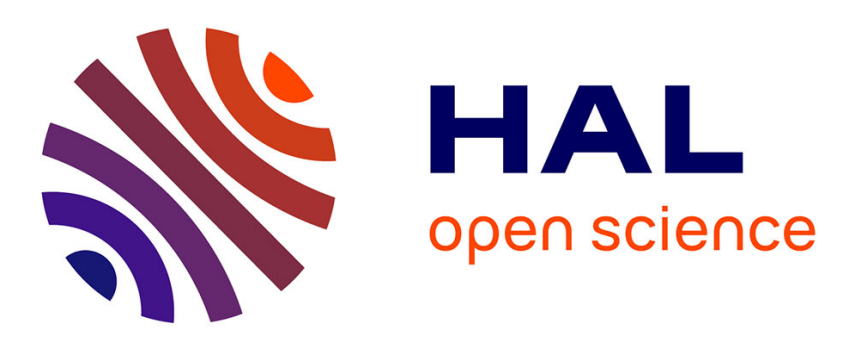

\title{
Improved quality in the hospital discharge summary reduces medication errors-LIMM: Landskrona Integrated Medicines Management
}

Anna Bergkvist, Patrik Midlöv, Peter Höglund, Lisa Larsson, Åsa Bondesson, Tommy Eriksson

\section{To cite this version:}

Anna Bergkvist, Patrik Midlöv, Peter Höglund, Lisa Larsson, Åsa Bondesson, et al.. Improved quality in the hospital discharge summary reduces medication errors-LIMM: Landskrona Integrated Medicines Management. European Journal of Clinical Pharmacology, 2009, 65 (10), pp.1037-1046. 10.1007/s00228-009-0680-1 . hal-00534973

\section{HAL Id: hal-00534973 https://hal.science/hal-00534973}

Submitted on 11 Nov 2010

HAL is a multi-disciplinary open access archive for the deposit and dissemination of scientific research documents, whether they are published or not. The documents may come from teaching and research institutions in France or abroad, or from public or private research centers.
L'archive ouverte pluridisciplinaire HAL, est destinée au dépôt et à la diffusion de documents scientifiques de niveau recherche, publiés ou non, émanant des établissements d'enseignement et de recherche français ou étrangers, des laboratoires publics ou privés. 


\title{
Improved quality in the hospital discharge summary reduces medication errors-LIMM: Landskrona Integrated Medicines Management
}

\author{
Anna Bergkvist • Patrik Midlöv • Peter Höglund • \\ Lisa Larsson • Åsa Bondesson • Tommy Eriksson
}

Received: 17 December 2008 / Accepted: 1 June 2009 /Published online: 26 June 2009

(C) Springer-Verlag 2009

\begin{abstract}
Purpose We have developed a model for integrated medicines management, including tools and activities for medication reconciliation and medication review. In this study, we focus on improving the quality of the discharge summary including the medication report to reduce medication errors in the transition from hospital to primary and community care.

Methods This study is a longitudinal study with an intervention group and a control group. The intervention group comprised 52 patients, who were included from 1 March 2006 until 31 December 2006, with a break during summer. Inclusion in the control group was performed in the same wards during the period 1 September 2005 until 20 December 2005, and 63 patients were included in the
\end{abstract}

\footnotetext{
A. Bergkvist $(\bowtie)$

Hospital Pharmacy, University Hospital MAS,

20502 Malmö, Sweden

e-mail: anna.bergkvist@med.lu.se

A. Bergkvist $\cdot \AA$. Bondesson $\cdot$ T. Eriksson

Department of Clinical Sciences in Lund, Lund University,

Lund, Sweden

P. Midlöv

Department of Clinical Sciences in Malmö - General

Practice/Family Medicine, Lund University,

Lund, Sweden

P. Höglund

Department of Clinical Pharmacology, Lund University Hospital,

Lund, Sweden

L. Larsson $\cdot$ Å. Bondesson · T. Eriksson

Hospital Pharmacy, Lund University Hospital,

Lund, Sweden
}

control group. In order to improve the quality of the medication report, clinical pharmacists reviewed and gave feedback to the physician on the discharge summary before patient discharge, using a structured checklist. Medication errors were then identified by comparing the medication list in the discharge summary with the first medication list used in the community health care after the patient had returned home.

Results By improving the quality of the discharge summary, patients had on average $45 \%$ fewer medication errors per patient $(P=0.012)$. The proportion of patients without medication errors was $63.5 \%$ in the control group and $73.1 \%$ in the intervention group. However, this increase was not significant $(P=0.319)$. Patients who used a specific medication dispensing system (ApoDos) had a 5.9-fold higher risk of suffering from medication errors than those without this medication dispensing system $(P<0.001)$.

Conclusion Review and feedback on errors in the discharge summary, including the medication report and a correct medication list, reduced medication errors during the transfer of information from hospital to primary and community care.

Keywords Elderly · Hospital discharge $\cdot$ Inpatients · Medication errors $\cdot$ Medication reconciliation .

Medication report

\section{Introduction}

In the elderly, the risk of medication errors increases with the number of home medications when admitted to or discharged from hospital [1]. Medication errors can lead to 
severe consequences for the patient, and $20-30 \%$ of medication errors have been assessed as potential adverse drug events [2]. A review article reports that of the medication errors identified, $11-59 \%$ were thought to be of clinical importance [3]. Various types of medication errors are frequent in hospitals $[4,5]$ and in the interface between care levels [6-16]. Insufficient quality in the transfer of information on a patient's medications has recently been highlighted as one of the most important problems in health care, and international and national programs have been developed for information and help [16]. According to the Institute for Healthcare Improvement, poor communication of medical information at transition points is responsible for as many as $50 \%$ of all medication errors and $20 \%$ of adverse drug events in the hospital [11].

In order to provide appropriate and correct treatment for the patient and ensure good patient safety, effective communication between the different care levels is crucial. In Sweden, as in many other parts of the world, each care level does not always possess the complete information on a patient's medical history, as many care units have their own medical records. The risk of medication errors occurring, and thus morbidity as a consequence of medication errors, is therefore high. Risks of reduced patient safety as a consequence of poor communication are well documented and reported. A step towards improved patient safety is harmonising the use of medical records so that the hospital and primary care can access the same information. Recently this has been introduced in Sweden and is now used by 4 of 21 counties [17].

A previous study made by our research group, which addressed medication errors caused by insufficient transfer of information when changing care level, showed that information on every fifth medication was transferred erroneously [18]. At admission to hospital, 29 of 34 patients had at least one medication error and corresponding results at discharge from hospital to community health care showed 19 of 35 patients with errors [18]. As a consequence of the study, a discharge summary with a medication report was developed at Lund University Hospital to reduce transfer errors. This document is written for the patient and contains the following [19]:

- General information (reason for admission to hospital, planned follow-up)

- Medication report (a section with information on changes that were made to the medication therapy and reasons for these changes)

- Medication list (a list of current medications, dosages and indications for each medication)
At discharge, the document is given to the patient and, if applicable, sent to the community health-care provider and the patient's general practitioner.

The first evaluation of this medication report was made at Lund University Hospital and showed that medication reconciliation using a medication report significantly reduced both the total number of medication errors as well as the number of medication errors with moderate and high risk for clinical consequences [19]. The medication report has also been shown to significantly reduce morbidity and thus the need for medical care due to medication errors in the elderly [20]. However, the study did not evaluate the content and correctness of the medication report, so there is room for further improvement in the process, which is the basis for this study.

This study is part of an integrated medicines management investigation (the LIMM study), in which a multiintervention process approach to drug therapy was used. This has been shown to improve the quality and appropriateness of the prescription of medication to the elderly [21]. The aim of this study was to investigate whether the process improves the quality of the discharge summary and if this process development also reduces medication errors when patients are discharged from hospital.

\section{Methods}

\section{Study design}

This study is a longitudinal study with an intervention group and a control group. Patients in the control group were included at the same wards prior to the intervention period.

The ethics committee at Lund University had no objections to the study, and it was performed in accordance with Swedish ethics legislation and the Declaration of Helsinki.

Setting and study population

Patients admitted to the Department of Internal Medicine at Landskrona Hospital in the county of Skåne in southern Sweden were the source for inclusion. The clinic comprises three wards with 61 beds in total. The hospital and the primary care clinics do not have access to the same medical records.

\section{Quality improvement of the information in the discharge summary}

Patients eligible for inclusion were identified from the intervention group in the multi-intervention study [21]. 
Inclusion criteria for the multi-intervention study were patients 65 years or older and living in the towns of Landskrona or Svalöv, including patients discharged to the community health care as well as those without help from the community health care. Patients were included from 1 March 2006 until 31 December 2006, with a break during summer (from 1 June 2006 until 31 August 2006). Inclusion was done continuously and systematically during the study period.

\section{Medication errors when discharged from hospital to community health care}

The same intervention group was used as for "Quality improvement of the discharge summary", with the additional criteria that the patient had to be discharged to community health care.

Patients in the control group were included from 1 September 2005 until 20 December 2005.

At inclusion, the patient received oral and written information about the study from the pharmacist and at acceptance, the patient was asked to give written consent to participate in the study. When it was not possible to communicate with the patient, a next of kin was asked instead. Patients in terminal stages of their disease were excluded for ethical reasons.

\section{Intervention}

During the intervention period, the pharmacists took part in the daily work at the three wards and performed structured interventions in order to increase the appropriateness of the drug treatment [21]. Several interventions were performed by the pharmacists. At admission, medication reconciliation was performed in order to identify the correct patient medication list, problems with handling, knowledge, compliance and attitudes towards the drug treatment. The patient's potential drug-related symptoms were checked. A medication review was performed in order to further identify drug-related problems and inappropriate drug use. Based on identified problems, a systematic medication care plan was created in which all changes to the medication therapy were noted. The care plan was updated continuously and was decided on by the team. The pharmacists took an active role in patient information and education, based on specially developed drug information leaflets, with focus on new medications.

A physician completed the discharge summary (Appendix 1), including the medication report and a medication list, at the day of discharge, and the pharmacist then evaluated the document according to a developed checklist (Appendix 2), with focus on correctness of the medication report and the medication list. The pharmacist used the medication interview, the care plan, as well as other medical records from the hospital stay, to evaluate the information in the discharge summary. If information was lacking or was incorrect, the pharmacist discussed this with the physician who was then able to adjust the document before the patient was discharged.

\section{Measures}

\section{Quality improvement in the information in the discharge} summary

Data were collected on discrepancies found between the information in the discharge summary and the systematic medication care plan as well as other medical records from the patient's hospital stay. The checklist (Appendix 2) was developed and accepted at Lund University Hospital as a standard and a tool to measure and follow-up on important features and errors in the writing of the discharge summary. For the medication report, the standard was that all final changes in medication made during the hospital stay and the reason for them should be documented. For the medication list, a complete list of all current medications and the indication, reason, or disease state should be documented. A total score of the quality, including general information, could also be calculated.

In order to study discrepancies that were considered more important than others, information was collected on which discrepancies the physicians chose to adjust or not.

\section{Medication errors when discharged from hospital to community health care}

Discharge summaries were written by a physician for all patients, but only evaluated by a pharmacist during the intervention period. The medication list in the discharge summary from the hospital was compared with the first medication list used by the community health care after discharge in order to study whether the transfer of information was done correctly. Some patients received medications from a specific medication dispensing system (ApoDos), in which a regional pharmacy ApoDos dispensing unit prepared the dosages and provided the patients with a complete list of all medications used by the patient. Other patients did not use this system and for them, the community health care had medication lists that they filled out manually.

The same definition of medication error and the same checklist for documenting the errors as in previous studies were used [18, 19]. The definition states that a medication 
error is any error in the process of prescribing, dispensing or administering a drug, whether there are adverse consequences or not [22]. In this study, we focused on the discrepancies in the medication reconciliation discharge process, and a medication error was defined as occurrence of one of the following discrepancies together with the lack of documentation to indicate that the change in the medication therapy was done deliberately.

- A medication was missing in the medication list from the community health care.

- A medication had been added to the medication list from the community health care.

- The total dosage over $24 \mathrm{~h}$ had been changed in the medication list from the community health care.

Generic substitution of a medication was not considered an error in the reconciliation process.

When the patient was transferred to the community health care, nurses were asked to send in the first medication list used after the patient arrived. If no medication list was received from the community health care, reminders were sent out repeatedly. Identification of medication errors was done prospectively in both groups. Two pharmacists evaluated the transfer of information independently, and their evaluations were compared and consensus was reached.

\section{Study size calculation}

In a previous study in Landskrona (in which the medication report was not used), $46 \%$ of the patients had no discrepancies between their medication list at discharge and their medication list after returning to community health care [18]. Later on, in a study at the University Hospital in Lund (USiL) in which the medication report had already been in use for 6 months, $66 \%$ of the patients had no medication errors when transferred from hospital to community health care [19]. We assumed that the results from the study at USiL were similar to the baseline in this study. As the discharge summary, including the medication report, was evaluated at discharge in this study, we expected a further increase in the prevalence of patients without medication errors from 66 to $90 \%$. With $5 \%$ significance $(P=0.05)$ and power $=80 \%, 46$ patients were needed in both groups.

Data analyses

If not stated otherwise, the results are given as mean and SD.

Computer software $\mathrm{R}$ version 2.5.1 (R Foundation for Statistical Computing, Vienna, Austria) was used for all statistical analyses. The $\mathrm{R}$ COIN procedure (asymptotic linear-by-linear association test) was used to analyse whether there was a significant difference between the two groups regarding the proportion of patients without medication errors. The $\mathrm{R}$ COIN procedure implements a unified approach for conditional inference procedures. In this study, we used the asymptotic linear-by-linear association test for ordered categorical data. The Poisson regression test was used to compare the number of medication errors per patient in the groups.

\section{Results}

In the intervention group, discharge summaries for a total of 172 patients were evaluated. Of these, 52 patients were also included in the intervention group in the investigation of medication errors when transferring from hospital to community care. The control group for the investigation of medication errors consisted of 63 patients, for whom the discharge summaries were not evaluated.

Quality improvement of the information in the discharge summary

Table 1 shows the result of the evaluation of the medication report and the medication list and the extent to which the physician adjusted the discrepancies identified by the pharmacist. Only 1 out of 172 discharge summaries was without discrepancies according to the evaluation checklist. Discrepancies in general information

Table 1 Number and type of discrepancies between the discharge summary and the medical records and the extent to which they were adjusted by the physician prior to discharge, distributed over the different sections in the discharge summary (general information and layout excluded)

\begin{tabular}{llll}
\hline & $\begin{array}{l}\text { At } \\
\text { evaluation }\end{array}$ & $\begin{array}{l}\text { After } \\
\text { adjustment by } \\
\text { the physician }\end{array}$ & $\begin{array}{l}\text { Adjustments } \\
\text { made }\end{array}$ \\
\hline $\begin{array}{l}\text { Medication report, } \\
\text { changes made (\%) }\end{array}$ & 198 & 159 & $39(20)$ \\
$\begin{array}{c}\text { Medication report, } \\
\text { reason for the } \\
\text { changes made (\%) }\end{array}$ & 259 & 230 & $29(11)$ \\
$\begin{array}{c}\text { Medication list, current } \\
\text { medications (\%) }\end{array}$ & 159 & 65 & $94(59)$ \\
$\begin{array}{c}\text { Medication list, } \\
\text { indication for current } \\
\text { medications (\%) }\end{array}$ & 153 & 111 & $42(27)$ \\
\hline
\end{tabular}


were seldom put forward to the physician, so a total scoring was not possible to calculate. When disregarding this and layout issues, 46 discharge summaries out of 172 were complete and correct.

Regarding the medication report, the pharmacist did not always inform the physician about the identified discrepancies, and in these cases the physician was given no chance to adjust the information. This was seen for $33 \%$ of the medication reports with discrepancies. As the information sometimes was included in the document but not in the way stated by the checklist, the pharmacists chose to put forward only discrepancies that risked having a major negative effect on the patient's drug treatment. A tight time schedule did not allow for all discrepancies to be discussed. The most frequent discrepancy in the medication list was that medications were missing. The reason was that the physician had discontinued the medication without noting this in the medical records. This was the case for $29 \%$ of the medication lists with discrepancies.

Medication errors when discharged from hospital to community health care

As presented in Table 2, the patients had similar baseline characteristics except for whether they were transferred to a nursing home or their own home. This could indicate that the patients in the intervention group were more seriously ill.

Table 2 Baseline characteristics at discharge for patients included in the investigation of medication errors when transferring from hospital to community health care

\begin{tabular}{|c|c|c|}
\hline & $\begin{array}{l}\text { Intervention } \\
\text { group } \\
(n=52)\end{array}$ & $\begin{array}{l}\text { Control } \\
\text { group } \\
(n=63)\end{array}$ \\
\hline Age (years) & $84(6.2)$ & $84(6.7)$ \\
\hline Sex: women $(\%)$; men $(\%)$ & $\begin{array}{l}37(71.2) \\
15(28.8)\end{array}$ & $\begin{array}{l}38(60.3) ; \\
25(39.7)\end{array}$ \\
\hline $\begin{array}{l}\text { Transferred to: nursing home (\%); } \\
\text { their own home with help (\%) }\end{array}$ & $\begin{array}{l}45(86.5) \\
7(13.5)\end{array}$ & $\begin{array}{l}48(76.2) ; \\
15(23.8)\end{array}$ \\
\hline $\begin{array}{l}\text { Using medication dispensing system } \\
\text { after discharge }(\%)\end{array}$ & $14(26.9)$ & $23(36.5)$ \\
\hline $\begin{array}{l}\text { Medications for continuous use at } \\
\text { discharge, mean (SD) }\end{array}$ & $8.6(4.2)$ & $7.6(3.3)$ \\
\hline $\begin{array}{l}\text { Medications for on-demand use at } \\
\text { discharge, mean (SD) }\end{array}$ & $1.4(1.5)$ & $1.1(1.5)$ \\
\hline $\begin{array}{l}\text { Medications for continuous use in } \\
\text { community health care, mean (SD) }\end{array}$ & $8.3(4.3)$ & $7.7(3.2)$ \\
\hline $\begin{array}{l}\text { Medications for on-demand use in } \\
\text { community health care, mean (SD) }\end{array}$ & $1.3(1.4)$ & $1.5(1.6)$ \\
\hline
\end{tabular}

The primary research question was whether our intervention decreased the number of medication errors at discharge from hospital to the community care. The total number of medications with medication errors decreased from $12.0 \%$ in the control group to $4.8 \%$ in the intervention group, as seen in Table 3. In the intervention group, the number of medication errors per patient was decreased by $45 \%, P=0.012$. Also the proportion of patients without medication errors was improved with an absolute increase of 9.6 , from $63.5 \%$ in the control group to $73.1 \%$ in the intervention group. However, this increase was not significant $(P=0.319)$.

Dividing the population into patients with ApoDos and patients without ApoDos showed that patients with ApoDos had a 5.9-fold higher risk of suffering from medication errors than those without this medication dispensing system $(P<0.001)$.

In the control group, the patients had on average 1.05 medication errors. The errors included commission errors ( 0.68 per patient), erroneous changes in dosage $(0.24$ per patient), and omission errors (0.13 per patient). Corresponding values for the intervention group were $0.48,0.17,0.17$, and 0.14 .

Errors in the transfer of information for approximately one-fifth of the patients were evaluated differently by the pharmacists. The evaluations were compared and consensus was reached.

\section{Discussion}

Our intervention decreased the number of medication errors per patient. There was an increase in the proportion of patients without errors, although this was not statistically significant. Limitations in the process, as described below, and also too low a power to detect a significant difference might be the explanation. We have previously developed and shown that the medication report in a discharge summary decreases medication errors, clinical consequences, and health contacts due to errors occurring when patients are discharged from hospital to community health care $[18,19]$. This study shows a further decrease in error rates by improving the internal hospital discharge process.

In 2000-2001, we performed a descriptive but otherwise identical study in the same setting to describe the medication error rates [18]. The proportion of medications with medication errors after discharge and return to primary care was $17 \%$ and only $46 \%$ of the patients had no error at all. In this study the error rates for all medications were $12 \%$ in the control group and $4.8 \%$ in the intervention group. The proportions of patients 
Table 3 Medication errors identified by the pharmacist when comparing the medication list in the discharge summary with the medication list in the community health care, as well as number of medications at discharge and in community health care, in the intervention group and the control group

\begin{tabular}{|c|c|c|c|c|c|c|}
\hline & \multicolumn{3}{|c|}{ Intervention group } & \multicolumn{3}{|c|}{ Control group } \\
\hline & $\begin{array}{l}\text { All } \\
(n=52)\end{array}$ & $\begin{array}{l}\text { Medication } \\
\text { dispensing system } \\
\text { excluded }(n=38)\end{array}$ & $\begin{array}{l}\text { Medication } \\
\text { dispensing system } \\
\text { only }(n=14)\end{array}$ & $\begin{array}{l}\text { All } \\
(n=63)\end{array}$ & $\begin{array}{l}\text { Medication } \\
\text { dispensing system } \\
\text { excluded }(n=40)\end{array}$ & $\begin{array}{l}\text { Medication } \\
\text { dispensing system } \\
\text { only }(n=23)\end{array}$ \\
\hline $\begin{array}{l}\text { Patients without medication } \\
\text { errors }(\%)\end{array}$ & $38(73.1)$ & $35(92.1)$ & $3(21.4)$ & $40(63.5)$ & $32(80.0)$ & $8(34.8)$ \\
\hline $\begin{array}{l}\text { Patients with at least one } \\
\text { medication error }(\%)\end{array}$ & $14(26.9)$ & $3(7.9)$ & $11(78.6)$ & $23(36.5)$ & $8(20.0)$ & $15(65.2)$ \\
\hline $\begin{array}{l}\text { Patients with at least three } \\
\text { medication errors }(\%)\end{array}$ & $3(5.8)$ & 0 & $3(21.4)$ & $11(17.5)$ & $3(7.5)$ & $8(34.8)$ \\
\hline $\begin{array}{l}\text { Patients with at least five } \\
\text { medication errors }(\%)\end{array}$ & $1(1.9)$ & 0 & $1(7.1)$ & $5(7.9)$ & $1(2.5)$ & $4(17.4)$ \\
\hline $\begin{array}{l}\text { Medications for continuous use } \\
\text { at discharge, mean (SD) }\end{array}$ & $8.6(4.2)$ & $7.9(4.1)$ & $10.5(4.1)$ & $7.6(3.3)$ & $6.7(2.9)$ & $9.2(3.3)$ \\
\hline $\begin{array}{l}\text { Medications for on-demand use } \\
\text { at discharge, mean (SD) }\end{array}$ & $1.4(1.5)$ & $1.2(1.4)$ & $1.9(1.6)$ & $1.1(1.5)$ & $0.9(1.4)$ & $1.4(1.5)$ \\
\hline $\begin{array}{l}\text { Medications for continuous } \\
\text { use in community health care, } \\
\text { mean (SD) }\end{array}$ & $8.3(4.3)$ & $7.5(4.1)$ & $10.4(4.0)$ & $7.7(3.2)$ & $6.9(2.9)$ & $9.2(3.2)$ \\
\hline $\begin{array}{l}\text { Medications for on-demand use } \\
\text { in community health care, } \\
\text { mean (SD) }\end{array}$ & $1.3(1.4)$ & $1.2(1.4)$ & $1.7(1.4)$ & $1.5(1.6)$ & $1.2(1.5)$ & $2.1(1.6)$ \\
\hline Medications & 520 & 346 & 174 & 549 & 305 & 244 \\
\hline $\begin{array}{l}\text { Medications with medication } \\
\text { errors }(\%)\end{array}$ & $25(4.8)$ & $4(1.2)$ & $21(12.1)$ & $66(12.0)$ & $19(86.2)$ & $47(19.3)$ \\
\hline
\end{tabular}

without medication errors were 63.5 and $73.1 \%$ for the control and intervention groups, respectively. In another larger study in a similar setting at a university hospital, the proportions of patients without errors were 34 and $68 \%$ before and after introduction of the medication report in the discharge summary [19]. There are strong similarities in the activities, in the error rates, and in the type of errors between the control group in this study and in the intervention group from the latter study. However in the latter study, we did not evaluate the quality of the discharge summary, and the errors were measured at discharge based on the discharge summary and not when patients returned to primary care as was the case in this study. The latter study also showed a reduction in clinical consequences based on medication errors [20]. In our previous descriptive study, there were an average of 2.4 medication errors per patient at admission to the hospital, and only $15 \%$ of the patients had no errors at all [18]. In this study, a medication interview [15] was performed and a correct medication list was created and used for each patient as part of the pharmacist's responsibilities in the LIMM model. Also a systematic medication care plan was set up and used for follow-up and documentation of activities during the patient hospital stay. This model was shown to improve medication appropriateness and was very appreciated by the team [21].

Computerised medical records are a prerequisite for the hospitals, the primary care, and the community care to access the same information. In Sweden, $88 \%$ of the hospitals have computerised medical records, in comparison with the rest of Europe and the United States where the numbers are 51 and $12 \%$ respectively [17]. With this in mind, Sweden seems to have better possibilities for providing the health-care system access to the same information. However, it is important to state that IT does not solve all problems connected to communicating and documenting problems in the use and handling of drugs. It has been stated that electronic communication between the GP and the community pharmacists improves agreement but does not suffice as a solution for obtaining reliable information [23]. Also GPs found discharge content more important than delivery method [24].

Medication reconciliation has been introduced as one of the solutions to decrease medication errors and increase patient safety [9-11]. The process involves comparing the 
medications a patient is receiving to what he or she actually should be receiving and then resolving the discrepancies [11].

Studies from the UK, Holland, Canada and the U.S. have been based on development of models for medication reconciliation at hospital discharge. This includes telephone follow-up by a pharmacist [12], and discharge summaries to pharmacies [13, 14, 25-29] and to the general practitioner $[27,28,30]$. To our knowledge, our discharge summary is the first systematic tool enabling information to be produced for the patient and to the next level of care by the responsible person, the physician. We have previously shown the benefit of this $[18,19]$. Now we provide evidence for the additional benefit of the pharmacists' involvement in the quality assurance of the medication reconciliation process.

Although the impact of ApoDos on the discharge process was not the primary research question, we analysed this since in a previous study we showed that ApoDos was a risk factor for medication errors [18]. Another reason for analysing the groups separately was the differences between patients with and without ApoDos, such as number of medications and handling of medications. As in the previous study in the same setting, we found the ApoDos system to increase the risk of medication errors, especially in the control group. The difference between the two groups is probably that the clinical pharmacist better identified patients with ApoDos at hospital admission and also highlighted this at discharge when the regional pharmacy ApoDos dispensing unit is to be contacted. It is interesting to note that only 3 of 38 patients in the intervention group without ApoDos had a total of four errors at discharge, and the error rate for all medications was $1.2 \%$. It is therefore tempting to conclude that the LIMM model together with a focus on improving errors in the handling of the ApoDos system offers the potential to be a very safe system for medication use in the interface between primary and hospital care.

Limitations of the study

This is a study based on a new team approach for improving the patient's drug therapy. As part of the approach, we are focusing on reducing medication errors in the transition of care by improving the medication reconciliation process. Based on this, we could not randomise care by patient, or by clusters of physicians, pharmacists or wards. We could have selected a control group at another hospital, but based on lack of resources and also potential differences in baseline (we believed that our department had few errors), we did not.
We have not included holiday periods during which staffing can change or be insufficient. However since we have different time periods to some extent for the groups, this could have affected the results.

To our knowledge there are no other confounders, such as organisational changes in the health-care system or changes in the handling of discharge information in the hospital or primary care, which can explain the differences in the results.

Future needs

There is room for improvement in the process of evaluating the discharge summary, and this could decrease the errors even further. In general the quality control and suggestions for change provided by clinical pharmacists were accepted and corrected especially for the medication list but also for the medication report. However, information and education on how to write the discharge summary, agreement on which discrepancies to prioritise and timing of the interventions should be improved to improve the process of communication so that the physician can make more corrections before discharge.

In two studies, we have shown ApoDos to be a risk factor for medication errors at discharge from hospital to community care. This process needs to be further investigated to identify the reason for these errors and to study methods for improvement.

\section{Conclusions}

Quality control of the patient's discharge summary with correction of errors prior to the patient's hospital discharge reduced medication errors in primary and community care. The quality control and suggestions for change were accepted and corrected by the physician, if communicated by the pharmacist.

Acknowledgements First, we would like to thank the students Helena Lindholm and Cecilia Bergkvist for collecting the majority of the data. We would also like to thank the staff at the Department of Internal Medicine at Landskrona Hospital, especially Dr Per Löfdahl, the nurses in the community health care, and the clinical pharmacists Sofia Jönsson and Emma Olsson for excellent cooperation and work.

Funding We are grateful to the National Board of Health and Welfare, the Swedish Academy of Pharmaceutical Sciences, the County of Skåne and Apoteket $\mathrm{AB}$ for funding the study. 


\section{Appendix 1}

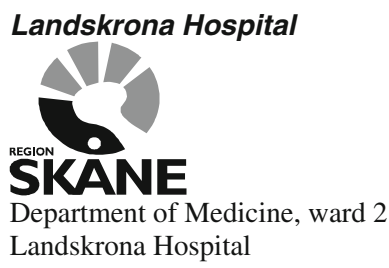

Physician during hospital care: Mats Matsson General practitioner: Olle Olsson

Hospital care: 1 Jan 2008 - 11 Jan 2008
Born: 1 Jan 1921

Name: Clara Carlsson

\section{DISCHARGE SUMMARY}

You have been in hospital care because you have experienced dizziness for a period of time and finally you fainted. When you fainted you fell and now suffer from back pain. Your blood pressure was found to be too low and this could explain the dizziness. Your medications have therefore been adjusted and your blood pressure is now back to normal. During your hospital care we also found that you had an infection in the urinary tracts, for which you now are receiving antibiotics.

After discharge, you will return to the nursing home Flower garden. Within three weeks you will have an appointment with your General Practitioner, who will measure and follow up on your blood pressure and back pain.

\section{$\underline{\text { Medication Report }}$}

- Metoprolol has been decreased from 2 to 1 tablets per day, due to low blood pressure.

- Furosemide has been discontinued since you no longer have a problem with swollen ankles.

- Paracetamol has been added because of the back pain from your fall.

- Cefadroxil has been added due to a urinary tract infection.

\begin{tabular}{|l|l|l|l|l|l|l|}
\hline $\begin{array}{l}\text { MEDICINE } \\
\text { preparation and dose }\end{array}$ & Effect & Morning & Noon & Evening & Night & Comments \\
\hline Tabl Metoprolol 25 mg & $\begin{array}{l}\text { Lowers blood } \\
\text { pressure }\end{array}$ & 1 & & & & \\
\hline Tabl Hydrochlorothiazide $50 \mathrm{mg}$ & $\begin{array}{l}\text { Lowers blood } \\
\text { pressure }\end{array}$ & 1 & & & & \\
\hline Tabl Metformin $850 \mathrm{mg}$ & Against diabetes & 1 & & 1 & & \\
\hline Tabl Paracetamol $500 \mathrm{mg}$ & $\begin{array}{l}\text { Against back } \\
\text { pain }\end{array}$ & 2 & 2 & 2 & 2 & On demand \\
\hline Tabl Cefadroxil $500 \mathrm{mg}$ & $\begin{array}{l}\text { Against urinary } \\
\text { tract infection }\end{array}$ & 1 & & 1 & & Until 13 January \\
\hline
\end{tabular}




\section{Appendix 2}

\section{Checklist for quality assessment \\ Discharge summary with Medication Report according to the Lund model}

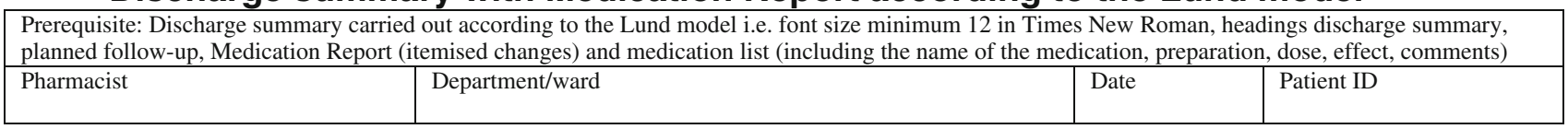

\begin{tabular}{|l|l|l|l|l|}
\hline & \multicolumn{3}{|c|}{ Summary } \\
\hline & & $\begin{array}{l}\text { Points, if } \\
\text { correct }\end{array}$ & $\begin{array}{l}\text { Number of } \\
\text { observed errors }\end{array}$ & $\begin{array}{l}\text { Total number of points } \\
\text { (=correct - number of errors) }\end{array}$ \\
\hline 1 & Contents & 10 & & \\
\hline 2a & Medication Report - changes made & 5 & & \\
\hline 2b & Medication Report - reason for the changes made & 5 & & \\
\hline 3a & Medication list - current medication & 5 & & \\
\hline 3b & Medication list - indication for current medications & 5 & & \\
\hline \multicolumn{4}{|c|}{ Total score; (maximum 30, minimum 0) } & $=$ \\
\hline
\end{tabular}

\begin{tabular}{|r|l|l|l|}
\hline 1. & Contents & No & Comments \\
\hline A & Is the patient's name and social security number correctly stated? & -1 & \\
\hline B & Is the Discharge summary limited to one page? & -1 & \\
\hline C & Does the Discharge summary contain information on reason for admission? & -1 & \\
\hline D & Does the Discharge summary contain information on the hospital care? & -1 & \\
\hline E & Is the name of the physician during hospital care stated? & -1 & \\
\hline F & Is the name of the general practitioner stated? & -1 & \\
\hline G & Is the hospital care stated as date, month and year? & -1 & \\
\hline H & Does the Discharge summary contain information on planned follow-up? & -1 & \\
\hline I & Do the sentences in the Medication Report begin with the name of the medicine? & -1 & \\
\hline J & Is the full name of the preparation stated (no abbreviations, but tabl, caps, supp is OK)? & -1 & \\
\hline \multicolumn{2}{|l|}{ Number of errors (No) } & & \\
\hline
\end{tabular}

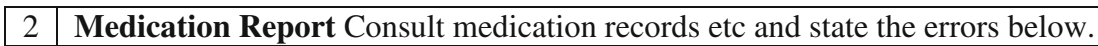

a. Changes made (changes to the medication therapy

during the hospital stay that are not correctly stated) b. Reason for the changes made (reasons for the changes in drug therapy are lacking)

3 Medication list. State the discrepancies, based on medications on the day of discharge and the Medication Report, below.

a. Current medications (medicine, dose or comments are not correctly stated) b. Indication for the medication therapy is not described with words understandable for the patient. 


\section{References}

1. Kwan Y, Fernandes OA, Nagge JJ, Wong GG, Huh JH, Hurn DA, Pond GR, Bajcar JM (2007) Pharmacist medication assessments in a surgical preadmission clinic. Arch Intern Med 167(10):10341040. doi:10.1001/archinte.167.10.1034

2. Lisby M, Nielsen LP, Mainz J (2005) Errors in the medication process: frequency, type, and potential clinical consequences. Int J Qual Health Care 17(1):15-22. doi:10.1093/intqhe/mzi015

3. Tam VC, Knowles SR, Cornish PL, Fine N, Marchesano R, Etchells EE (2005) Frequency, type and clinical importance of medication history errors at admission to hospital: a systematic review. CMAJ 173(5):510-515. doi:10.1503/cmaj.045311

4. Dean B, Schachter M, Vincent C, Barber N (2002) Prescribing errors in hospital inpatients: their incidence and clinical significance. Qual Saf Health Care 11(4):340-344

5. Runciman WB, Roughead EE, Semple SJ, Adams RJ (2003) Adverse drug events and medication errors in Australia. Int J Qual Health Care 15(Suppl 1):i49-59

6. Wilson S, Ruscoe W, Chapman M, Miller R (2001) General practitioner-hospital communications: a review of discharge summaries. J Qual Clin Pract 21(4):104-108

7. Gleason KM, Groszek JM, Sullivan C, Rooney D, Barnard C, Noskin GA (2004) Reconciliation of discrepancies in medication histories and admission orders of newly hospitalized patients. Am J Health Syst Pharm 61(16):1689-1695

8. Paulino EI, Bouvy ML, Gastelurrutia MA, Guerreiro M, Buurma H (2004) Drug related problems identified by European community pharmacists in patients discharged from hospital. Pharm World Sci 26(6):353-360

9. Cua YM, Kripalani S (2008) Medication use in the transition from hospital to home. Ann Acad Med Singapore 37(2):136-136

10. Poole DL, Chainakul JN, Pearson M, Graham L (2006) Medication reconciliation: a necessity in promoting a safe hospital discharge. J Healthc Qual 28(3):12-19

11. Institute for Healthcare Improvement (2008) Medication reconciliation review. http://www.ihi.org/IHI/Topics/PatientSafety/MedicationSystems/Tools/Medication+Reconciliation+Review.htm. Accessed 28th August 2008

12. Dudas V, Bookwalter T, Kerr KM, Pantilat SZ (2001) The impact of follow-up telephone calls to patients after hospitalization. Am J Med 111: 26S-30S doi: 10.1016/S0002-9343(01)00966-4

13. Duggan C, Feldman R, Hough J, Bates I (1998) Reducing adverse prescribing discrepancies following hospital discharge. Int $\mathrm{J}$ Pharm Pract 6:77-82

14. Paquette-Lamontagne N, McLean WM, Besse L, Cusson J (2001) Evaluation of a new integrated discharge prescription form. Ann Pharmacother 35(7-8):953-958

15. Bondesson A, Hellström L, Eriksson T, Höglund P (2009) A structured questionnaire to assess patient compliance and beliefs about medicines taking into account the ordered categorical structure of data. J Eval Clin Pract (in press)
16. Council of Europe (2006) Creation of a better medication safety culture in Europe: building up a safer medication practice. Expert group on safe medication practices. http://wwwcoeint/t/e/social_cohesion/soc-sp/Medication $\% 20$ Safety $\% 20$ culture $\% 20$ report $\%$ 20E.pdf. Accessed 8 Apr 2009

17. Jerlvall L, Pehrsson T (2008) IT support in the counties (in Swedish). Swedish Association of Local Authorities and Regions, Stockholm

18. Midlov P, Bergkvist A, Bondesson A, Eriksson T, Hoglund P (2005) Medication errors when transferring elderly patients between primary health care and hospital care. Pharm World Sci 27(2):116-120

19. Midlov P, Holmdahl L, Eriksson T, Bergkvist A, Ljungberg B, Widner H, Nerbrand C, Hoglund P (2008) Medication report reduces number of medication errors when elderly patients are discharged from hospital. Pharm World Sci 30(1):92-98. doi:10.1007/s11096-007-9149-4

20. Midlov P, Deierborg E, Holmdahl L, Hoglund P, Eriksson T (2008) Clinical outcomes from the use of medication report when elderly patients are discharged from hospital. Pharm World Sci 30:840-845. doi:10.1007/s11096-008-9236-1

21. Bergkvist A, Midlov P, Hoglund P, Larsson L, Eriksson T (2009) A multi-intervention approach on drug therapy can lead to a more appropriate drug use in the elderly. J Eval Clin Pract (in press)

22. Leape LL (1995) Preventing adverse drug events. Am J Health Syst Pharm 52(4):379-382

23. van der Kam WJ, Meyboom de Jong B, Tromp TF, Moorman PW, van der Lei J (2001) Effects of electronic communication between the GP and the pharmacist. The quality of medication data on admission and after discharge. Fam Pract 18(6):605609

24. Pillai A, Thomas SS, Garg M (2004) The electronic immediate discharge document: experience from the South West of Scotland. Inform Prim Care 12(2):67-73

25. Booij AD, de Boer WO, Kokenberg ME, Tromp TF (2003) Interventions in seamless care. Pharm World Sci 25(2):4142

26. Dvorak SR, McCoy RA, Voss GD (1998) Continuity of care from acute to ambulatory care setting. Am J Health Syst Pharm 55 (23):2500-2504

27. Bolas H, Brookes K, Scott M, McElnay J (2004) Evaluation of a hospital-based community liaison pharmacy service in Northern Ireland. Pharm World Sci 26(2):114-120

28. Cameron B (1994) The impact of pharmacy discharge planning on continuity of care. Can J Hosp Pharm 47(3):101-109

29. Al-Rashed SA, Wright DJ, Roebuck N, Sunter W, Chrystyn H (2002) The value of inpatient pharmaceutical counselling to elderly patients prior to discharge. Br J Clin Pharmacol 54 (6):657-664. doi:10.1046/j.1365-2125.2002.01707

30. Sandler DA, Heaton C, Garner ST, Mitchell JR (1989) Patients' and general practitioners' satisfaction with information given on discharge from hospital: audit of a new information card. BMJ 299(6714):1511-1513 